\title{
An Oxidation Study of NiCoCrAl Coatings Produced by Electrolytic co-Deposition Method
}

\author{
K.O. OSKAY ${ }^{a, *}$ AND B. DEMIREL ${ }^{b}$ \\ ${ }^{a}$ Department of Metallurgical \& Materials Engineering, Cumhuriyet University, 58140 Sivas, Turkey \\ ${ }^{b}$ Department of Materials Science \& Engineering, Erciyes University, 38280 Kayseri, Turkey \\ $\mathrm{NiCoCrAl}$ metallic compounds are used as bond coats for thermal barrier coatings. These composite coatings \\ were obtained by electrodeposition under DC conditions from a Watts bath containing suspended $\mathrm{Cr}$ and $\mathrm{Al}$ \\ particles. Electrodeposition of a composite coating is a low-cost method to produce bond coats for thermal barrier \\ coatings. The co-deposition studies were performed by using an Inconel 718 substrate. Oxidation resistance and \\ microstructural study are discussed in this study.
}

DOI: 10.12693/APhysPolA.134.186

PACS/topics: electrolytic co-deposition, bond coat

\section{Introduction}

Hot section parts of gas turbines, such as blades and vanes, are exposed to high temperature in service. Thermal barrier coatings (TBC) are used to shield the metallic substrate, such as nickel based super alloy, providing thermal and oxidation protection. TBCs usually consist of two coatings: a thermally insulating ceramic topcoat, and a bond coat (BC). A slow growth barrier layer, generally of $\mathrm{Al}_{2} \mathrm{O}_{3}$, is needed to be formed since this layer is the most important part of the TBC system during oxidation providing adhesion between the $\mathrm{TBC}$ and the substrate [1].

$\mathrm{MCrAl}$ coatings (where $\mathrm{M}$ represents $\mathrm{Ni}$ or $\mathrm{Co}$ ) are commonly used as BC to protect super alloys at elevated temperatures above $900^{\circ} \mathrm{C} . \mathrm{BC}$ are generally deposited by APS, high velocity oxyfuel, low pressure plasma spray, cathodic arc/ion plasma deposition or by EB-PVD [2].

The electrolytic co-deposition process is an alternative method which offers low cost of bond coat deposition. Besides, with this technique, all surfaces exposed to liquid electrolyte are coated, including blind holes, where the liquid can penetrate [3]. However, the commercial potential of this method for TBC system has not been fully realized due to the lack of information about the oxidation resistance.

Several researchers have evaluated bond coatings for thermal barrier coating (TBC) by electrodeposition techniques [4-6]. The growth rate and spallation resistance of alumina scales can vary widely depending on the composition [7]. Different coating compositions provide different protective properties due to the nature of the different oxides growing on them. Many studies are reported about oxidation behavior of NiCoCrAl coating produced with other techniques (plasma spray, EB-PVD). However, there are no sufficient

\footnotetext{
*corresponding author; e-mail: kursadoskay@gmail.com
}

reports concerning the effect of composition of the electrodeposited coating on the oxidation behavior.

Hence, the aim of this study was to investigate the oxidation behavior of $\mathrm{NiCoCrAl}$ composite coatings deposited by electrolytic co-deposition technique.

\section{Materials and equipment}

Nickel composite coating was prepared by using a Watts-type bath containing $240 \mathrm{~g} / \mathrm{l}$ of nickel sulphate $\left(\mathrm{NiSO}_{4} \cdot 6 \mathrm{H}_{2} \mathrm{O}\right), 50 \mathrm{~g} / \mathrm{l}$ of nickel chloride $\left(\mathrm{NiCl}_{2} \cdot 6 \mathrm{H}_{2} \mathrm{O}\right)$, $40 \mathrm{~g} / \mathrm{l}$ of boric acid $\left(\mathrm{H}_{3} \mathrm{BO}_{3}\right), 5-15 \mathrm{~g} / \mathrm{l}$ of cobalt sulphate $\left(\mathrm{CoSO}_{4} \cdot 7 \mathrm{H}_{2} \mathrm{O}\right) .0 .2 \mathrm{~g} / \mathrm{l}$ of surfactant were added. Analytical reagents and distilled water were used to prepare the plating solution.

A nickel sheet of $99.99 \%$ purity with dimensions of $250 \times 300 \times 100 \mathrm{~mm}^{3}$ was used as anode and the Inconel 718 with radius of $200 \mathrm{~mm}$ was used as cathode. For deposition of composite coatings, $\mathrm{Cr}(40 \mu \mathrm{m})$ and $\mathrm{Al}$ $(1 \mu \mathrm{m})$ particles were used. Samples were cleaned and activated according to ASTM B343 procedure. All coatings were fabricated using DC electrodeposition method at the current density of $8 \mathrm{~A} / \mathrm{dm}^{2}$ with deposition time of $45 \mathrm{~min}$ at $50^{\circ} \mathrm{C}$. The $\mathrm{pH}$ of the plating solution was maintained at 4 , which was adjusted by adding sulphuric acid or sodium hydroxide when necessary.

The composite plating was carried out in a beaker. The heated bath was stirred by a magnetic stirrer. The anode and cathode were vertically positioned in the bath. The samples were heat treated at $1000^{\circ} \mathrm{C}$ for two hours in argon atmosphere. The specimens were ultrasonically cleaned for SEM and XRD analysis. The phase composition of the deposits was characterized using X-ray diffraction (RIGAKU Miniflex 600) with $\mathrm{Cu} \mathrm{K}_{\alpha}$ radiation. The scan rate was $1^{\circ} / \mathrm{min}$ and $2 \theta$ ranged from $20^{\circ}$ to $80^{\circ}$. The isothermal oxidation tests were carried out in a muffle furnace at $950^{\circ} \mathrm{C}$.

\section{Results and discussion}

According to SEM images, both $\mathrm{Cr}$ and $\mathrm{Al}$ particles are well incorporated into the Ni matrix. As shown in 
Fig. 1 the spherical particles are uniformly distributed on the coarse particles. Firstly, chromium particles were absorbed by nickel atoms, then the nickel particles started to form slowly around the chromium particles through encapsulation and incorporation of other metal particles. The EDX analysis shows that the fine spherical particles are $\mathrm{Al}$ and the coarse particles are the $\mathrm{Ni}$ coated $\mathrm{Cr}$ particles. Table I shows the results of EDX analysis of the composite coatings. The EDX analysis was carried out at five different locations and the average value was taken.

TABLE I

Results of the EDX analysis of the as-deposited coatings

\begin{tabular}{c|c|c|c|c}
\hline \hline Sample No. & $\begin{array}{c}\mathrm{Ni} \\
\text { [wt.\%] }\end{array}$ & $\begin{array}{c}\mathrm{Co} \\
\text { [wt.\%] }\end{array}$ & $\begin{array}{c}\mathrm{Cr} \\
\text { [wt.\%] }\end{array}$ & $\begin{array}{c}\mathrm{Al} \\
\text { [wt.\%] }\end{array}$ \\
\hline $\mathrm{a}_{1}$ & 46 & 24 & 16 & 14 \\
$\mathrm{a}_{2}$ & 56 & 27 & 12 & 5 \\
$\mathrm{a}_{3}$ & 73 & 15 & 4 & 8 \\
$\mathrm{a}_{4}$ & 76 & 11 & 6 & 7
\end{tabular}

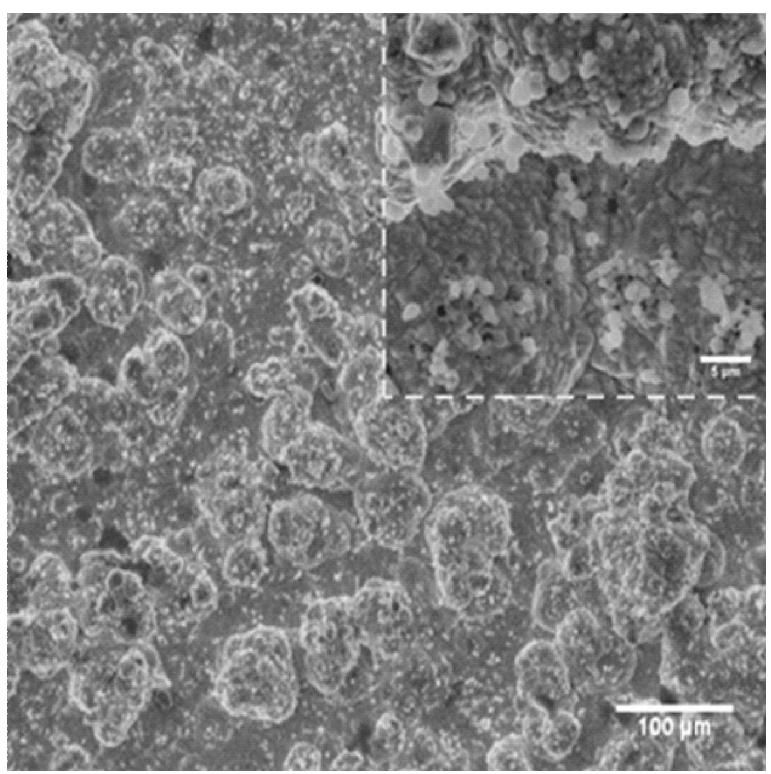

Fig. 1. Morphology of the as-deposited composite coating surface.

The $\mathrm{a}_{1}, \mathrm{a}_{2}, \mathrm{a}_{3}, \mathrm{a}_{4}$ samples were oxidized in air at $950^{\circ} \mathrm{C}$. Weight gain measurements of the oxidized samples were recorded and normalized per unit area to obtain the overall oxide growth rate. The weight gain curves for the electrodeposited composite coatings are shown in Fig. 2. The curves tend to follow parabolic rate law of oxidation. The maximum weight gains among the specimens was seen in $\mathrm{a}_{4}$ sample, which contains most cobalt.

While the TBC is in service, a thermally grown oxide (TGO) layer forms at the interface of the bond coat/top coat. This layer often plays an important role in the coating life and adherence of the TBC [8]. Thus TGO protects bond coat and the substrate from high temperature oxidation. On the other hand, TGO is the main source of residual stresses developed in TBC and may re- sult in coating failure, such as delamination and spallation [9]. Therefore, the TGO composition is a key factor for TBC system.

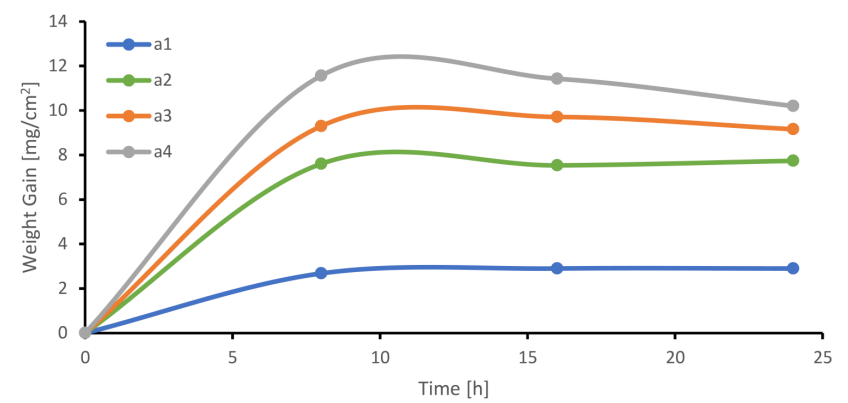

Fig. 2. Weight gain kinetics during isothermal oxidation at $950^{\circ} \mathrm{C}$.

Figure 3 shows XRD spectra of the samples oxidized at $950{ }^{\circ} \mathrm{C}$. The XRD result for $\mathrm{a}_{4}$ sample shows that the oxide structure includes $\mathrm{NiO}$ and $\mathrm{CoCr}_{2} \mathrm{O}_{4}$ spinel oxides formed on the coating. The lowest weight gains were seen in $\mathrm{a}_{1}$ sample. When the amount of $\mathrm{Al}$ was $14 \mathrm{wt. \%}$, $\mathrm{Al}$ was needed to form $\mathrm{Al}_{2} \mathrm{O}_{3}$. Figure 4c supports the $\mathrm{XRD}$ result, where the whisker-like $\mathrm{Al}_{2} \mathrm{O}_{3}$ is seen on the surface of the coating.

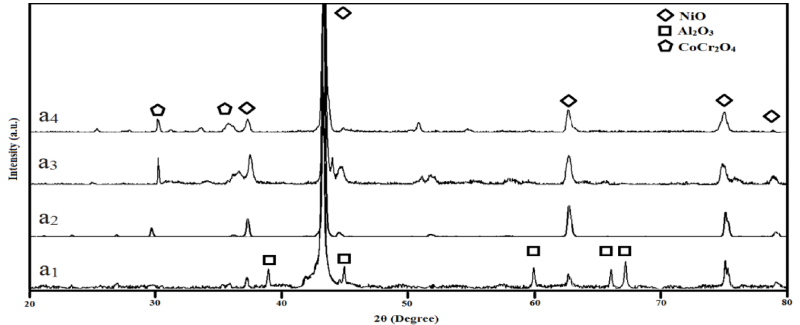

Fig. 3. XRD spectra of the oxidized samples.

The specimen with formed $\mathrm{Al}_{2} \mathrm{O}_{3}\left(\mathrm{a}_{1}\right)$ exhibits better oxidation resistance than the other specimens. This situation can be explained as follows. The mass gain of the coating is dependent on the composition of TGO. Nickel and cobalt based spinel type oxides (such as $\mathrm{NiCr}_{2} \mathrm{O}_{4}$, $\mathrm{CoCr}_{2} \mathrm{O}_{4}$ ) have substantially higher growth rates than $\mathrm{Al}_{2} \mathrm{O}_{3}$ and also a relatively large Pilling-Bedworth ratios (PBR, which is the volume ratio of the formed oxide to the metal consumed) [10].

The cross-section morphology of the sample oxidized in air is shown in Fig. 4a. The oxide scale consists of three layers. The outer layer mainly consists of $(\mathrm{Ni}, \mathrm{Co}) \mathrm{O}$, the intermediate layer consists of $\mathrm{Ni}, \mathrm{Co}, \mathrm{Cr}$ mixed spinel type oxides and the inner layer consists of $\mathrm{Cr}$ rich oxide crystals.

The SEM images support the XRD results with the exception of Fig. 4d. Figure 4d shows $\mathrm{Cr}$ rich oxide crystals in the cross section of the $a_{4}$ sample. The chromium oxide structure could not be seen in the XRD results. The reason of this is that the $\mathrm{Cr}$ oxide crystals were grown in the inner layer of the coating. Figure $4 \mathrm{~b}$ shows the sharp edged $\mathrm{NiO}$ crystals formed on the surface of the coating. 

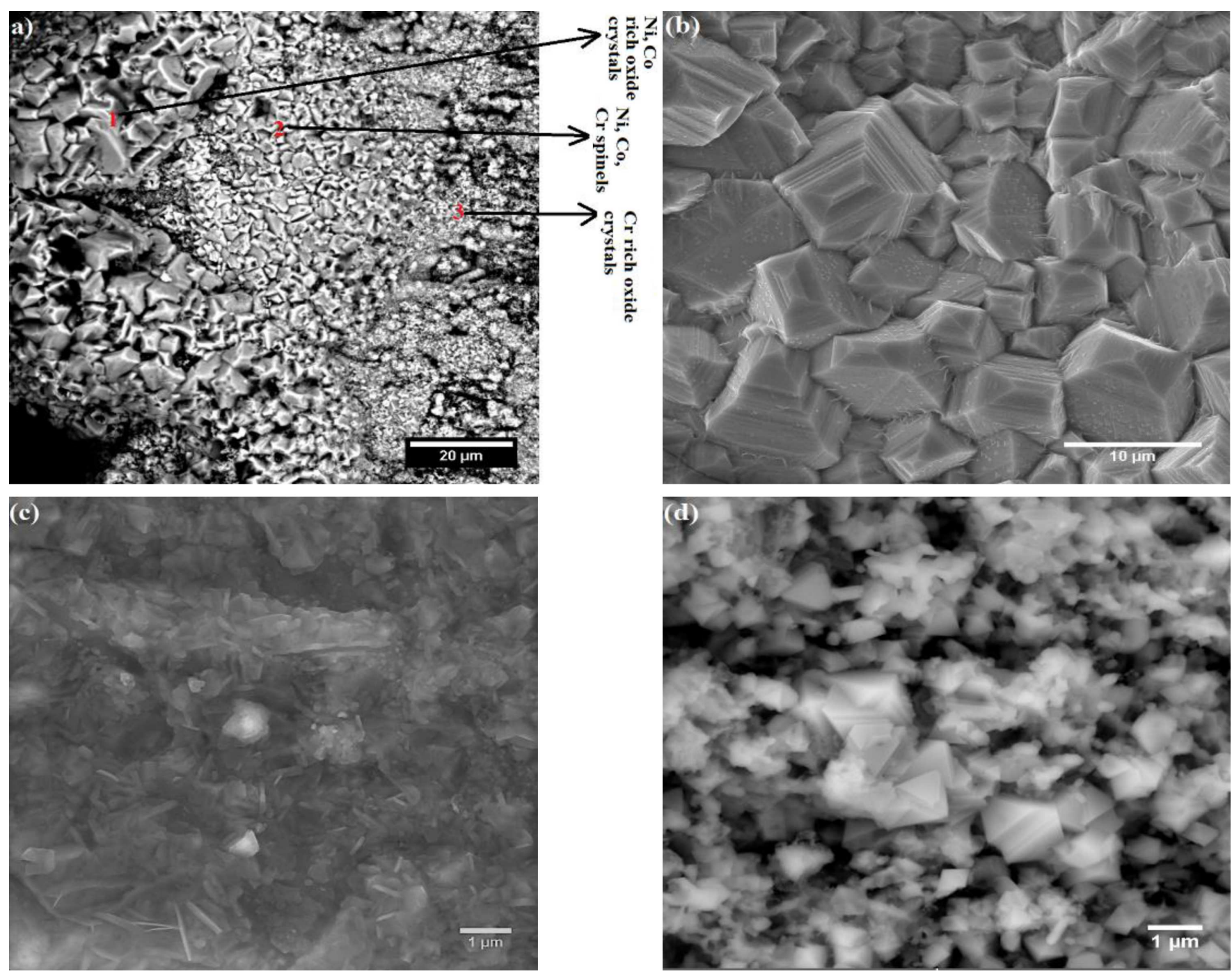

Fig. 4. Cross section morphology of the $a_{4}$ sample (a), surface morphology of the $a_{3}$ sample (b), surface morphology of the $a_{1}$ sample (c), cross section morphology of the $a_{2}$ sample $(d)$.

\section{Conclusions}

Using the electroplating method $\mathrm{Cr}$ and $\mathrm{Al}$ particles were assembled into $\mathrm{Ni}$, Co coating. It is an easy and cost effective method to produce bond coats for thermal barrier coatings. The results imply that the $\mathrm{Al}$ particles promote formation of $\mathrm{Al}_{2} \mathrm{O}_{3}$. SEM analysis shows that the chromium oxide scales are present inside the coating.

\section{Acknowledgments}

This work was supported by Research Fund of the Erciyes University. Project number FDA-2016-6752.

\section{References}

[1] M. Seraffon, N.J. Simms, J. Sumner, J.R. Nicholls, Oxid. Met. 81, 203 (2014).

[2] R. Darolia, International Materials Reviews, 58, 315 (2013).
[3] P.L. Fauchais, J.V.R. Heberlein, M.I. Boulos, Thermal Spray Fundamentals (Springer US, Boston, MA, 2014).

[4] M. Bahamirian, Iran. J. Mater. Sci. Eng. 10, 12 (2013).

[5] M. Srivastava, Siju, J.N. Balaraju, B. Ravisankar, J. Mater. Eng. Perform. 24, 1937 (2015).

[6] L.Z. Zhang, B.L. Bates, Y. Zhang, Surf. Eng. 33, 136 (2016).

[7] J.A. Hayness, B.A. Pint, W.D. Porter, I.G. Wright, Mat. at. High Temp. 21, 401 (2004).

[8] U. Schulz, C. Leyens, K. Fritscher, M. Peters, B. Saruhan-Brings, O. Lavigne, J.M. Dorvaux, M. Poulain, R. Mevrel, M. Caliez, Aerosp. Sci. Technol. 7, 73 (2003).

[9] C. Zhu, P. Li, X.Y. Wu, Ceram. Int. 42, 7708 (2015).

[10] W. Nowak, D. Naumenko, G. Mor, F. Mor, D.E. Mack, R. Vassen, L. Singheiser, W.J. Quadakkers, Surf. Coatings Technol. 260, 82 (2014). 